IMUESDAP AFTERNOON, JANUARY 15-SESSION OF THE PLANT

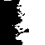
SECTION.

The Plant Section met in Chemical Hall, in connection with the Thio State Farmers' Institute.

The following papers were presented and discussed at the afternoon ession of the Plant Section. Interesting discussions ${ }^{1}$ were had at ill sessions of the section.

\title{
SOME RESULTS IN SELECTING RED CLOVER FOR DISEASE RESISTANCE.
}

By Samuel M. Bain and Samuel H. Essary, Knoxville, Tenn.

This paper, which is published in full in Bulletin No. 75 of the Tennessee Experiment Station (co-operating with the Plant Breeding If prestigations of the U. S. Department of Agriculture), gives the reialts of an apparently successful effort to produce an anthracnoseresistant strain of clover. The authors began about two years ago an ivestigation into the cause of the extensive failure of clover in Tenaessee in recent years, and soon reached the conclusion that a hitherto ondescribed fungous disease is chiefly responsible for the trouble. To aile fungus was assigned the name Colletotrichum trifolii.

In the late summer and autumn of 1905 about 200 selections were made of healthy clover plants growing surrounded by masses of plants killed by the disease. These selections were made at various points at an extreme distance apart of some 400 miles. In the spring of 1906 ifhese select seed were planted in rows 18 inches apart alternating with other rows planted with non-selected seed. Dead clover, raked up from inear-by clover field, where the crop was killed by the disease in the irevious season, was scattered over the plants in the entire plat. Alhough a large part of the young clover in the plat was destroyed by the clover weevil while the plants were in the seedling stage, enough rows were left at one end to make a satisfactory test.

By June 20, a remarkable contrast was evident between the select and the non-select rows, the former being green and healthy, while the latter were blackened and dying. The dead non-select plants fearing myriads of spores were removed and scattered over the select plants so as to test thoroughly their power of resistance. Although rrdinary plants at this season of the year will die within nine days ifter having spores sprayed upon them, very few of the select plants

1 As no reporter could be secured for these meetings, the Secretary egrets his inability to present these discussions to members receiving Volume III. Provision will be made at future meetings to secure the disऊựssions at all sessions. 
died of the disease. The select plants made a good crop of hay and produced a normal crop of seed, though in many cases traces of the disease were present. In many of the select plants not a trace of the disease was to be seen.

A most conservative estimate, made late in the following winter, places the odds in favor of the plants selected for non-resistance af 50 to 1 .

\section{IMPORTANCE OF THE MUTATION THEORY IN PRACTICAi, BREEDING.}

\section{By George Harbison ShuLc, Cold Spring Harbor, N. $\boldsymbol{Y}$.}

The time is long past when the practical man who is looking for immediate economic values is inclined to ignore the work done by the devotee of pure science. Conversely, the scientist appreciates as never before, the reciprocal relation existing between his work and that of the man who would turn every available resource to the production of something useful to man.

Nowhere is this improved relation between the theoretical and the practical better exemplified to-day than among breeders, and the establishment of the American Breeders' Association is a noteworthy indication of the existence of this improved condition. At the same time this organization fosters and promotes the reciprocity that shall increase the volume and the value of both scientific and economic breeding.

It is now a truism that all economic breeding must be in as great degree as possible scientific, and that all scientific breeding is likely to prove in the long run economic. Much of the scientific work being. done, seems rather remotely if at all economic, and it is not always easy to indicate wherein any specific result is of practical value. Experience has shown, however, that all science is so closely and so complexly interrelated, that few scientific researches are conducted, whose economic bearings do not sooner or later become manifest, though their true economic worth may not be recognized for years.

While it is not fair to the scientist to insist that he shall be able to point out the economic value of all of his results-in the search for truth he must not be so hampered-it is fair to ask of science that, when any of its results have a large and important bearing upon economic problems, these results shall be made as available as possible for the use of those who can turn them to immediato practical account:

The mutation theory, formulated by de Vries and supported by a great mass of data which he had gathered during twenty years of careful and energetic work, has this large bearing. It struck a funda mental key in biological science, and is now one of the principal foci about which biological research and controversy are centering. Aly most daily some new scientific support for the theory is given from 